\title{
Girdin knockdown promotes apoptosis in colorectal cancer via miR-29c-3p/Girdin axis
}

\author{
Junjiang Wang ${ }^{1,2 \#}$, Xiaowu $\mathrm{Li}^{3 \#}$, Yong $\mathrm{Li}^{2}$, Xueqing Yao ${ }^{1,2}$ \\ ${ }^{1}$ Department of General Surgery, The Second School of Clinical Medicine, Southern Medical University, Guangzhou 510515, China; ${ }^{2}$ Department \\ of General Surgery, Guangdong Provincial People's Hospital \& Guangdong Academy of Medical Sciences, Guangzhou 510080, China; ${ }^{3}$ Department \\ of General Surgery, The First Affiliated Hospital \& School of Clinical Medicine of Guangdong Pharmaceutical University, Guangzhou 510080, \\ China \\ Contributions: (I) Conception and design: J Wang, X Yao; (II) Administrative support: None; (III) Provision of study materials or patients: X Li, Y \\ Li;(IV) Collection and assembly of data: J Wang, X Li; (V) Data analysis and interpretation: All authors; (VI) Manuscript writing: All authors; (VII) \\ Final approval of manuscript: All authors. \\ "These authors contributed equally to this work. \\ Correspondence to: Xueqing Yao, MD, PhD. Department of General Surgery, The Second School of Clinical Medicine, Southern Medical University, \\ Guangzhou 510515, China; Department of General Surgery, Guangdong Provincial People's Hospital \& Guangdong Academy of Medical Sciences, \\ No. 106, Zhongshan 2 Road, Guangzhou 510080, China. Email: syyaoxueqing@scut.edu.cn.
}

Background: In recent years, the incidence and mortality of colorectal cancer (CRC) have increased year by year among young people. Increased levels of Girdin expression predict a poor prognosis of CRC, which presents a serious threat to human health globally. Herein, we investigated the role of Girdin in CRC and explored the underlying mechanisms in CRC.

Methods: The expression of Girdin was detected in human specimens. HCT116 cells with stably expressing or knock-out Girdin protein were successfully constructed to observe the biological function of gene. Protein expression was determined by immunohistochemistry, immunofluorescence and western blot.

Results: Clinically, overexpression of Girdin was observed in the tumor tissue and poor prognosis of CRC patients. Gain-of-function and loss-of-function assays showed that Girdin promoted CRC cell proliferation in vitro. Mechanistically, Girdin knock-down significantly enhanced apoptosis, the mitochondrial membrane potential dropped, and the reactive oxygen species increased greatly. Last but not least, we analyzed the TargetScan dataset and found that Girdin was a regulated target of hsa-miR-29c-3p in CRC. Luciferase reporter assay was used to verify the interaction between hsa-miR-29c-3p and the 3'UTR of Girdin.

Conclusions: Our findings suggest that Girdin has a crucial role in CRC progression via miR-29c-3p/ Girdin axis, highlighting Girdin as a therapeutic target for CRC.

Keywords: Colorectal cancer (CRC); Girdin; apoptosis; prognosis

Submitted Aug 23, 2019. Accepted for publication Nov 27, 2019.

doi: $10.21037 /$ tcr.2019.12.16

View this article at: http://dx.doi.org/10.21037/tcr.2019.12.16

\section{Introduction}

Colorectal cancer (CRC) is one of the most frequent malignant tumors of the digestive system and the fourth primary cause of cancer-related mortality (1). Approximately $40-50 \%$ of CRC cases are metastasized when diagnosed because of the absence of obvious early and specific symptoms and because the tumor cells invade adjacent tissues rapidly (2). Meanwhile, current surgical resection and chemotherapy do not work equally well for prognosis in all CRC patients. Therefore, it is significantly for us to explore original diagnostic markers and therapeutic targets in carcinoma of colon and rectum, which may supply a new direction for diagnosis and treatment of cancer metastasis.

Girdin, an actin-binding Akt substrate, is a 
multifunctional protein related to cell invasiveness and metastasis (3). Girdin expression is relatively high in breast cancer (4), gastric cancer (5), brain gliomas (6), and cervical cancer compared with healthy tissues (7). Also, the higher expression of the Girdin protein is closely associated with worse tumor prognosis in breast cancer and CRC (8). A preliminary experiment in our study also showed that the Girdin protein expression in colon cancer cells was significantly different from healthy colon cells. As a result, it is worth to investigate the regulatory mechanisms of Girdin in colorectal carcinomas.

MicroRNAs (miRNAs) are a unique group of small noncoding RNAs. These play an essential part in regulating gene expression through binding to the 3' untranslated regions (UTRs) of the targeted mRNA $(9,10)$. Research showed that miRNAs impacted tumor proliferation, apoptosis, and migration (11). For example, the expression for hsa-miR-29c-3p was reduced in the CRC tissues when compared to the matching non-cancerous tissue samples; hsa-miR-29c-3p may directly target SPARC whose silencing reduced cell proliferation and migration (12). Additionally, miR-29c-3p helps biological aging in human mesenchymal stem cells through a target procress of CNOT6 by the p53-p21 and p16-pRB pathways (13).

In this study, the mechanism of Girdin and hsa-miR-29c$3 p$ in CRC was explored. Our experimental results indicated that the hsa-miR-29c-3p/Girdin axis was a possible therapeutic target in carcinoma of colon and rectum.

\section{Methods}

\section{Cell culture}

The colon cancer cell lines HCT116, NCM460 were sourced by the American Type Culture Collection (ATCC, Manassas, USA). Culutring of the cells was done in in a Roswell Park Memorial Institute (RPMI) 1640 medium. A total of $10 \%$ fetal bovine serum (FBS) supplemented it in a $5 \% \mathrm{CO}_{2}$ atmosphere at $37{ }^{\circ} \mathrm{C}$.

\section{Analyzing the real time quantitative polymerase chain reaction ( $q R T-P C R)$}

The total RNA was isolated away from the tumor tissue samples using Trizol reagent (ET101, TransGen Biotech, CHINA). After, cDNA was synthesized (RR037A, TAKARA BIO, JAPAN) and amplified with a PCR kit (218073, QIAGEN, Germany). Next, three times repeating qRT-PCR. Actin was used for the reference control. Primers used for qRT-PCR were: Girdin, Sense: 5'-GACCAACTAGAGGGAACTCG-3' and Antisense: 5'-TACTTTGTTTCTGTGCCATT-3'; Actin, Sense: 5'-ACCACAGTCCATGCC ATCAC-3' and Antisense: 5'-CCACCACCCTGTTGCTGTA-3'.

\section{Analysis of proteins using western blot}

The cellular protein was removed using the RIPA lysis buffer in the presence of protease and phosphatase inhibitors. Samples comprising of $30 \mu \mathrm{g}$ protein were electrophoresed using a $10 \%$ or $8 \%$ sodium dodecyl sulfate-polyacrylamide gel. Afterwards the proteins were transferred to PVDF membranes. Target proteins were incubated with the corresponding primary antibodies overnight at $4{ }^{\circ} \mathrm{C}$ as follow: Girdin, 1:1,000; Bax, 1:1,000; Bcl-2, 1:1,000; Caspase-3, 1:1,000; Cleaved cas3, 1:1,000; Caspase-9, 1:1,000; Cleaved cas9, 1:1,000; $\beta$-actin, 1:1,000. Next they were incubated with the goat anti-rabbit horseradish peroxidase secondary antibody (Univ-bio, Shanghai, China). The bands were developed using the ECL chemiluminescent kit (ECL-plus, Thermo Scientific). Actin normalized the total protein levels. After changes for the fold were calculated.

\section{Immunobistochemistry}

Paraformaldehyde-fixed CRC tissue were analysed by immunohistochemistry using an StreptAvidin-Biotin Complex (SABC) kit (Boster Immuoleader, Fremont, CA, USA) according to the manufacturer's instructions. CRC tissue were incubated with a primary antibody (Girdin, $1: 1,000)$ for $1 \mathrm{~h}$ at $37^{\circ} \mathrm{C}$, followed by incubation with secondary antibodies for $1 \mathrm{~h}$ at room temperature.

\section{Lentivirus transfection}

To knockdown Girdin expression, HCT116 cells (maintained in $10 \% \mathrm{FBS}$ ) were grown in a complete medium. Also, the cells were kept at $37{ }^{\circ} \mathrm{C}$ in a $5 \% \mathrm{CO}_{2}$ incubator. Next, the cells were then transfected with a short hairpin RNA (shRNA) with the goal to target the CCDC88A mRNA (5'-GAAGGAGAGGCAACTGGAT-3', nucleotides 4166-4184). The lipofectamine 3,000 reagent was sourced from Invitrogen (Carlsbad, California, USA). The 6-well plates for the colon cancer cells at the exponential growth phase were plated for $24 \mathrm{~h}$ at a density 
of $0.5 \times 10^{5}$ cells $/ \mathrm{mL}$. After, the cells were transfected following protocols of the manufacturer.

\section{Cell viability assay}

The cell counting kit-8 (CCK-8) assay determined cell proliferation. After lentivirus transfection, HCT116 cells were seeded in 96 -well plates $\left(1 \times 10^{4}\right.$ cells/well $)$, and the absorption of the cells was measured using a CCK-8 kit (Dojindo, Japan) by protocols set by the manufacturer at diverse indicated time points. Wells were determined in triplicate for the multile treatment groups.

\section{Colony formation assays}

A total of $1 \times 10^{3}$ transfected cells were inoculated into 6-well plates with $2 \mathrm{~mL}$ RPMI1640 supplemented with $10 \%$ FBS for 14 days. A replacement of the medium occurred on each third day to perform the colony formation assay. Then, for forty minutes the final colonies were fixed in a $4 \%$ paraformaldehyde medium and stained with Giemsa (Sigma-Aldrich, USA). Using colony formation, the quantity of visibly stained colonies was decided. Wells were measured in triplicate for each group.

\section{Flow cytometric analysis}

HCT116 cells were plated into 6-well plates and treated for 48 h. Using AnnexinV-PE Reagent (KeyGENBioTECH, China) according to the manufacturer's instructions to evaluate the cell apoptosis. The stained cells were analyzed using a flow cytometer (BD Biosciences, USA).

\section{ROS analysis}

ROS generation in cells was determined via staining of cells with $20 \mu \mathrm{m}$ DCFDA for $30 \mathrm{~min}$ in the darkness. The cells are divided into the following groups: $a, \mathrm{NC} ; \mathrm{b}, \mathrm{NC}$ + Z-VAD-FMK; c, Girdin shRNA; d, Girdin shRNA + Z-VAD-FMK. After being stained with DCFDA, cultured cells were analyzed with a flow cytometer that had a 488$\mathrm{nm}$ argon laser as its light source for measuring DCF fluorescence intensity. The FL1 (FITC) channel measured the green fluorescence. WinMDI 2.8 software measured the mean fluorescence intensity (MFI) of the 10,000 cells. The data for MFI was normalized to the control levels and it was expressed as the relative fluorescence intensity (DCF).

\section{Mitochondrial membrane potential}

Analysis of mitochondrial membrane potential was carried out using JC-1 staining kit (Life Technology). Cultured cells were incubated with staining buffer at $5 \mu \mathrm{M}$ concentration at $37^{\circ} \mathrm{C}$ for 30 minutes. Then, stained cells were washed with $\mathrm{PBS}$ and analyzed using a flow cytometer.

\section{Dual-luciferase reporter}

The Dual-luciferase reporter assays were performed in HCT116 cells to determine the potential target of miR$29 c-3 p$. The binding site for miR-29c-3p in the 3'-UTR of Girdin was constructed by SAGENE (Guangzhou, China), cloned into the pmirGLO Dual-Luciferase vector. Seeding of cells was done at $1 \times 10^{4}$ cells-per-well in a 96-well plate. After, the cells were transfected the proper days using lipofectamine (Life Technologies, Carlsbad, USA) with the synthetic miRNA precursor miR-29c-3p containing the dual-luciferase reporter.

\section{Statistical analysis}

All of the experimental data is presented as the mean \pm standard deviations, and the tests were repeated three times. ANOVA carried out the one-way statistical analysis via the SPSS 20.0 (Chicago, IL, United States) statistical package. A $\mathrm{P}<0.05$ value was considered statistically significant.

\section{Results}

\section{Girdin is up-regulated in aggressive CRC and has a poor prognosis of CRC patients}

As the expression level of Girdin is high in most cancers, we detected it through various ways on CRC. qRT-PCR analysis confirmed that Girdin was up-regulated in the CRC tissues when it was compared to corresponding paratumor mucosa tissues of a panel of 8 specimens (Figure 1A). Moreover, the IHC and Western Blot analyses were used to understand the expression of Girdin for CRC tissues and the adjacent non-tumor mucosa. Eight pairs of additional CRC tissues with non-tumor mucosa were analyzed. Girdin protein was radically upregulated in the CRC tissues when they were compared with the corresponding non-cancerous colorectal tissues (Figure 1B). IHC results showed that the positive signal of Girdin in CRC tissues was much more than the adjacent non-tumor colorectal tissues (Figure 1C). 
A

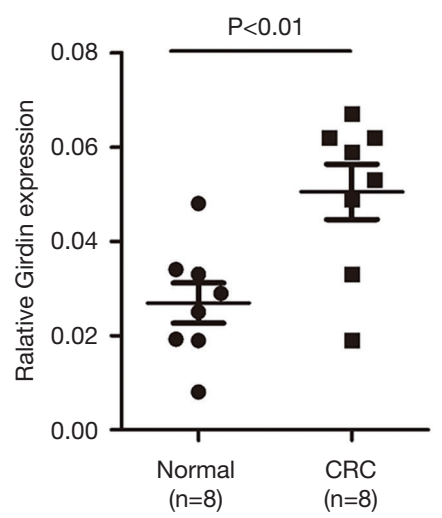

C

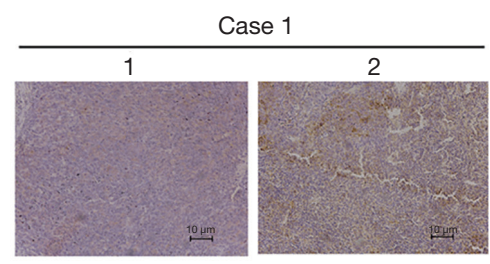

Case 2
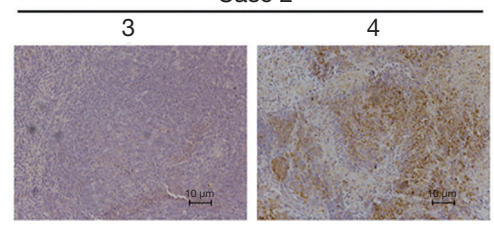

B

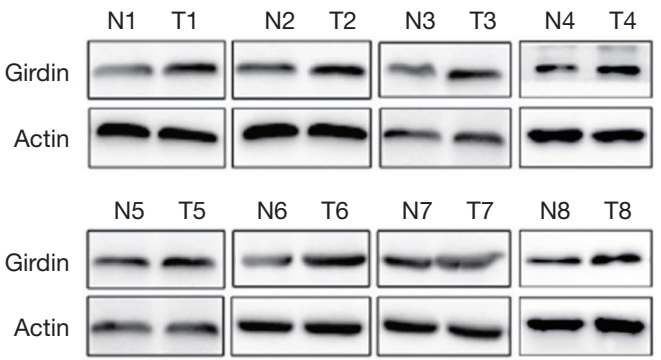

D

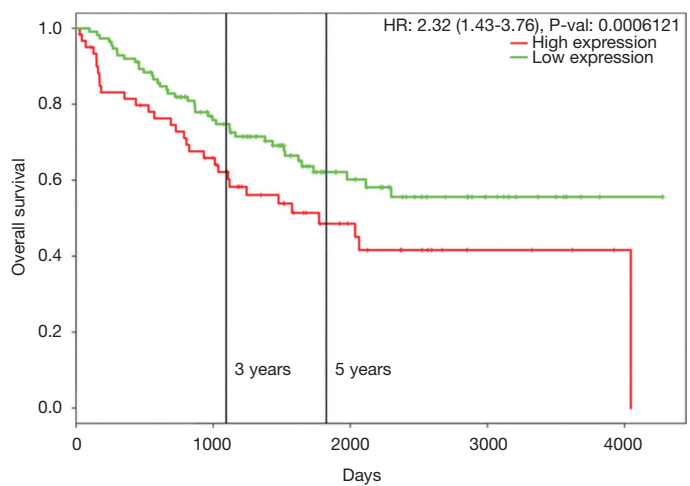

Figure 1 Girdin is upregulated in CRC and has a poor prognosis of CRC patients. (A) Girdin expression was analyzed using qRT-PCR in the samples of CRC and the adjacent non-tumor colorectal tissues (n=8). Girdin expression level was normalized to GAPDH. Results are shown as means \pm SD by two-tailed Student's $t$-test. $\mathrm{P}<0.01$. (B) Western blot analysis of Girdin in CRC tissues (T) and adjacent non-tumor tissues $(\mathrm{N})$. The relative protein abundance was determined by normalization with Actin. (C) Paraffin-embedded sections were stained with anti-Girdin antibodies. Visualizations of two representative cases were shown. 1,3 is adjacent non-tumor tissues; 2,4 is tumor tissues. (D) Effect of Girdin on patient survival via GEO dataset GSE24551. CRC, colorectal cancer; qRT-PCR, quantitative polymerase chain reaction.

Last but not least, in GEO dataset GSE24551, cancer tissues from 160 COAD patients were collected and detected by transcriptome chip assay. After followup of the confirmed patients, we found that patients with low expression $(n=80)$ of Girdin had a significantly longer survival time than those with high expression $(\mathrm{n}=80)$ (Figure 1D).

\section{Girdin promotes the progression of colon cancer cells in vitro}

To understand the biological characteristics of Girdin for CRC progression, we successfully built the Girdin overexpression lentivirus (LV-Girdin) and interference vector (shGirdin). qRT-PCR and western blot analysis was performed to detect the Girdin expression after transfection with overexpressed Girdin and interfered Girdin (Figure 2A,B). Cell-counting kit-8 and colony-forming assays were performed to reflect the cell proliferation ability. The results showed that cell viability was significantly increased after overexpression of Girdin, and it was decreased after interference (Figure 2C). The colony-forming assays supplied further evidence that Girdin promotes the progression of colon cancer cells in vitro (Figure 2D).

\section{Silencing of Girdin induced apoptosis in vitro}

To examine the influence of Girdin silencing on apoptosis, 
A

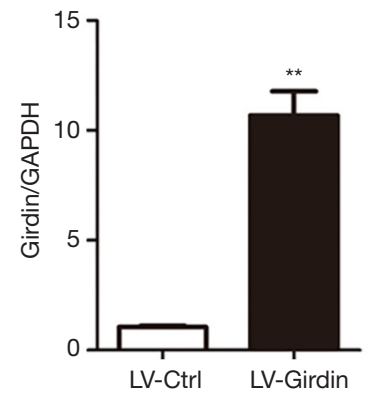

C
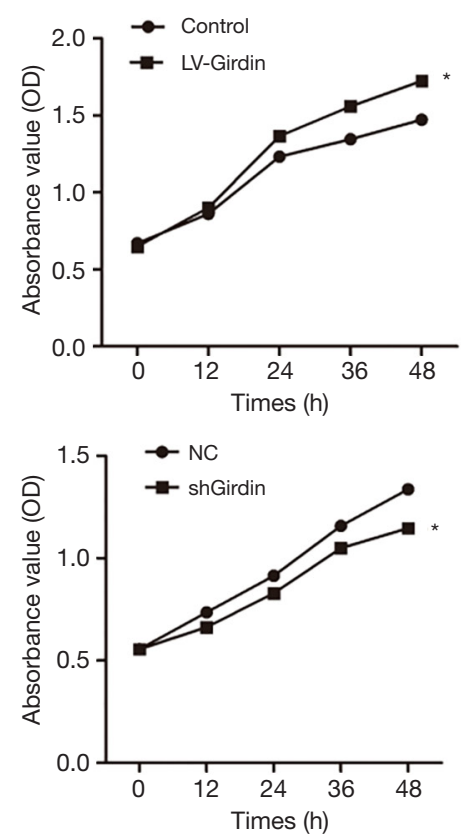

B

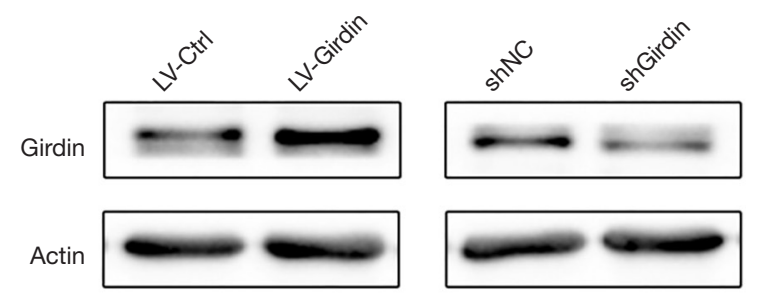

LV-Girdin
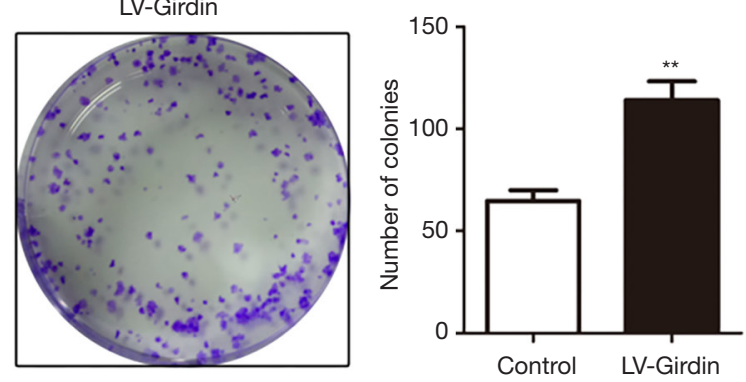

shNC
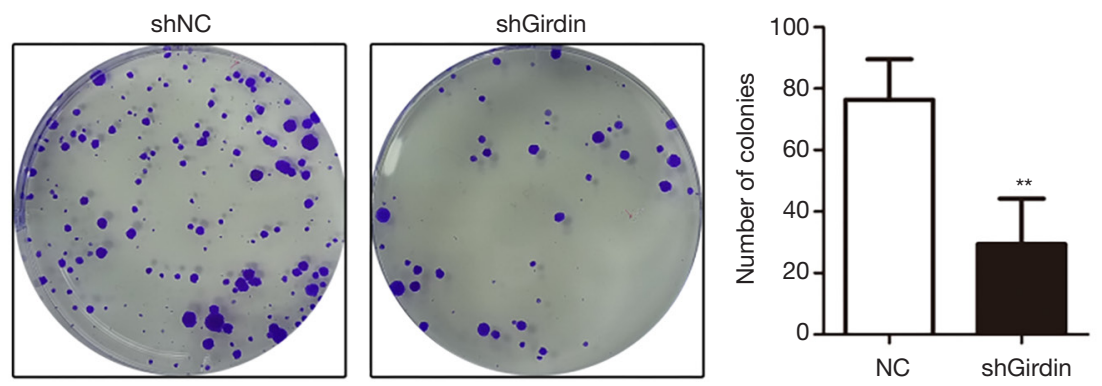

Figure 2 Girdin promotes the progression of CRC cells in vitro. (A) Real-time PCR and (B) western blot assay were used to verify the successful construction of Girdin overexpression and to silence CRC cells. (C) CCK8 assay was used to assess the ability of cell proliferation in indicated cells. Data are means $\pm \mathrm{SD},{ }^{*} \mathrm{P}<0.01$ as determined by one-way ANOVA. D. Colony formation assay of CRC cells transfected with lentivirus for Girdin. Bars on the right panel represent the number of formed clones. Results are shown as means $\pm \mathrm{SD}$. ${ }^{* *} \mathrm{P}<0.01$ by two-tailed Student's $t$-test. CRC, colorectal cancer.

flow cytometry assay were performed to screen the changes in morphology and quantify apoptosis. The results suggested that remarkable morphological changes in chromatin, like condensation and fragmentation, were seen in the Girdin-shRNA group compared with the healthy control group, while the differences were not visible when pretreating the cells with Z-VAD-FMK (Figure $3 A$ ). Similarly, compared with that in the healthy control group, the cell apoptotic rate in HCT116 cells transfected with the Girdin shRNA was significantly increased; however, it was decreased by treatment of with Z-VAD-FMK in the Girdin shRNA group (Figure 3B). Taken together, these results suggested that HCT116 cells transfected with shGirdin showed significantly increased apoptosis compared with healthy control cells, while apoptosis was reduced by pretreatment with Z-VAD-FMK. To identify the molecular mechanism of apoptosis in Girdin shRNAtransfected cells, Girdin and related proteins were detected by Western blotting. The results showed that caspase-3 and caspase- 9 were cleaved and that the ratio of $\mathrm{Bax} / \mathrm{Bcl}-2$ 

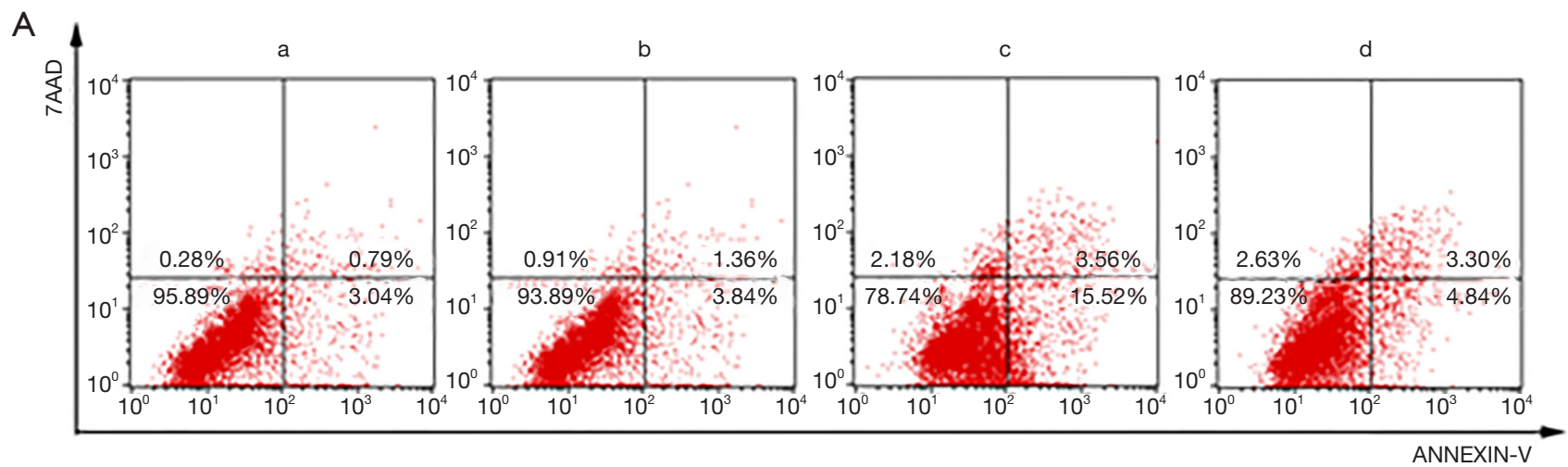

B

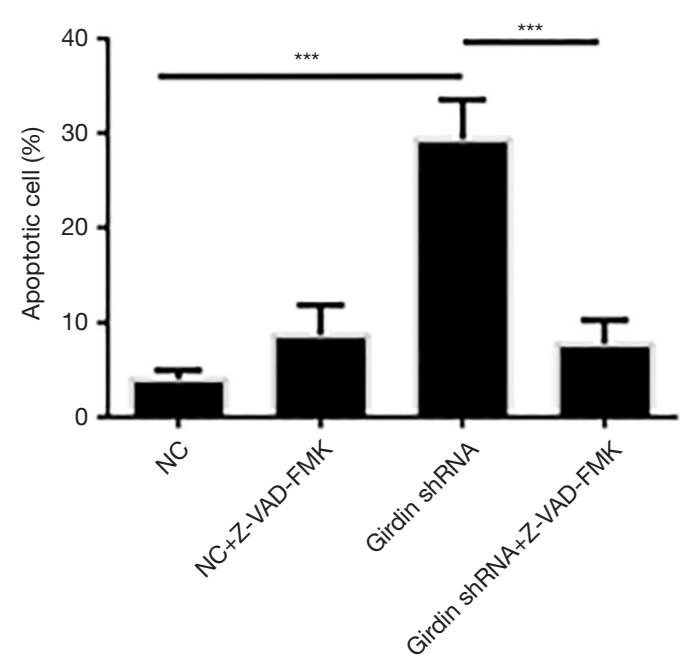

C

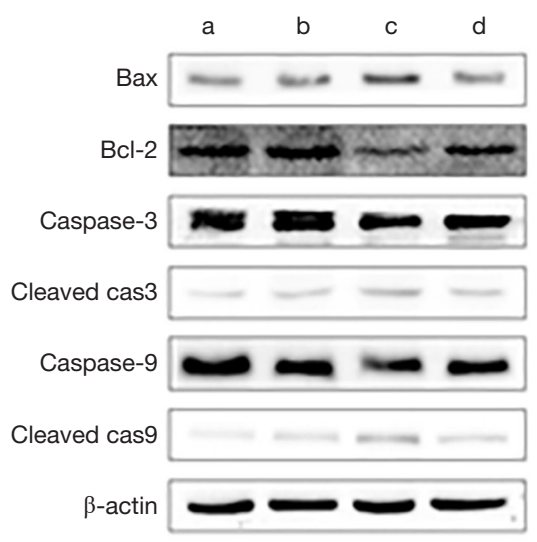

Figure 3 Silencing of Girdin induced apoptosis in vitro. (A) Flow cytometry was performed to detect the apoptosis rate related to Girdin silencing following treatment with Z-VAD-FMK. All experiments were repeated at least three times. (B) Bars below represent apoptotic cells. Results are shown as means $\pm \mathrm{SD}$. ${ }^{* * *} \mathrm{P}<0.001$ by one-way ANOVA. (C) Western blot analysis was performed to detect changes in the levels of Bax, Bcl-2, caspase-3, cleaved caspase-3, caspase-9, and cleaved caspase-9 following transfection with Girdin shRNA. a, NC; b, NC + Z-VAD-FMK; c, Girdin shRNA; d, Girdin shRNA + Z-VAD-FMK.

was significantly up-regulated after Girdin was knockdown but was down-regulated after treatment with Z-VAD-FMK (Figure 3C).

ROS level plays a crucial role in triggering apoptosis. ROS generation was detected for HCT116 cells using DCFDA staining that followed flow cytometry. The results show ROS generation was increased significantly in the Girdin-shRNA group compared with the healthy control group, while the ROS level was decreased after pretreatment with Z-VAD-FMK (Figure $4 A, B$ ). JC-1 is useful as a fluorescent probe to assess $\Delta \Psi \mathrm{m}$ (12). GirdinshRNA in the emission spectrum measured by flow cytometry showed the dissipation of $\Delta \Psi \mathrm{m}$ by GirdinshRNA in HCT116 cells but remained at an average level after pretreatment with Z-VAD-FMK in the Girdin shRNA group (Figure $4 C, D$ ). Taken together, these results show that Girdin silencing increased ROS generation and destroyed the mitochondrial membrane potential by activation of the caspase signaling pathway.

\section{Girdin was a regulated target of bsa-miR-29c-3p in CRC}

In terms of gene expression, transcriptional repression for miRNAs is believed to be a crucial regulatory tool. Algorithms which are publicly available for bioinformatics such as the TargetScan software, were used to search for upstream miRNAs for Girdin. hsa-miR-29c-3p was verified as an upstream regulator of Girdin. The expression of hsa- 


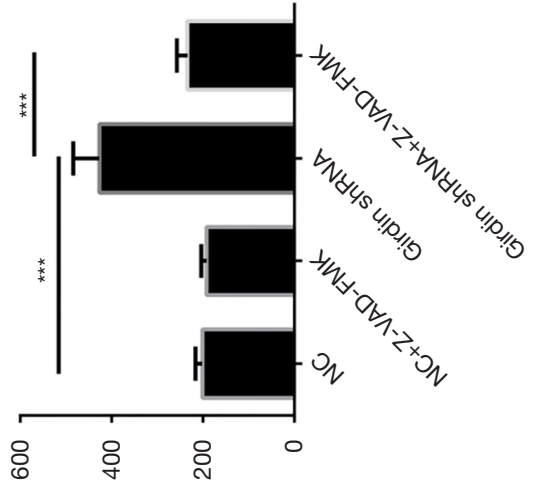

$\infty$

Kł! suəłu! әэuəosəxon!ł SOY
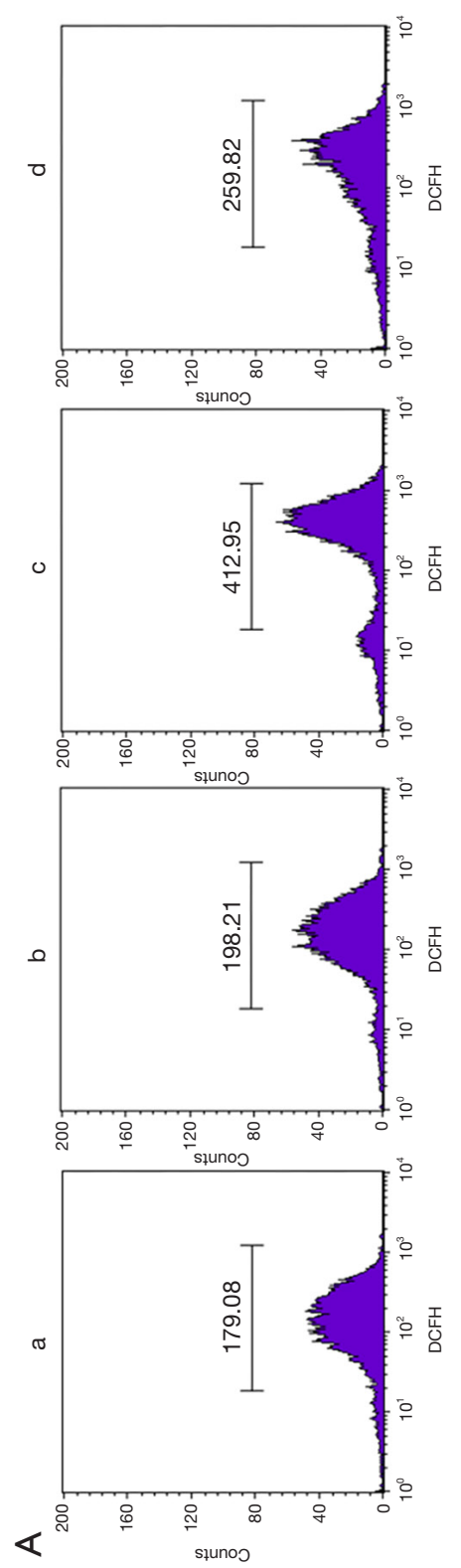
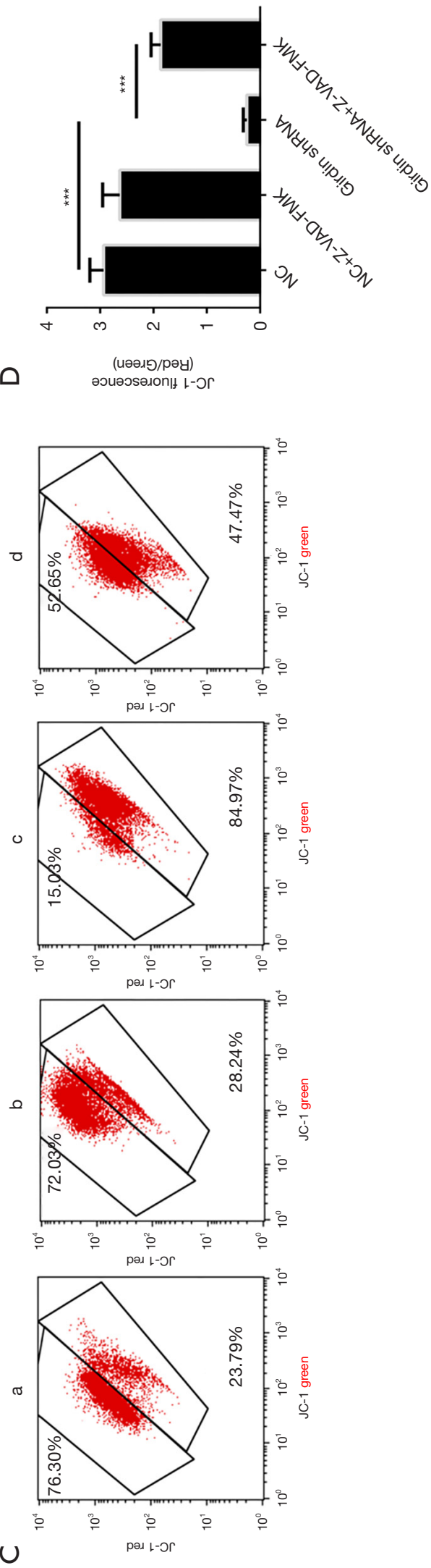

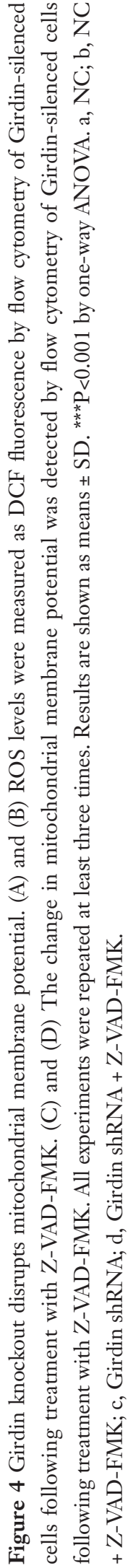

(c) Translational Cancer Research. All rights reserved. 
A

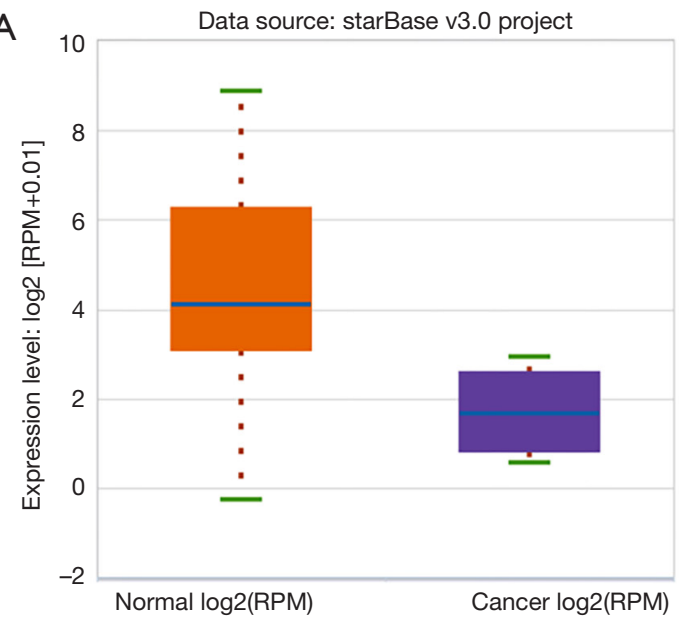

C

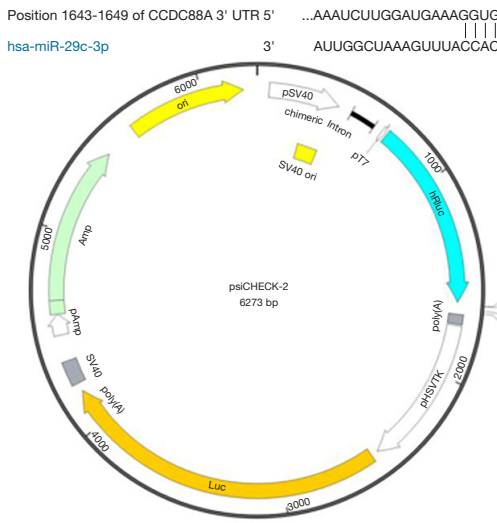

$\mathrm{E}$

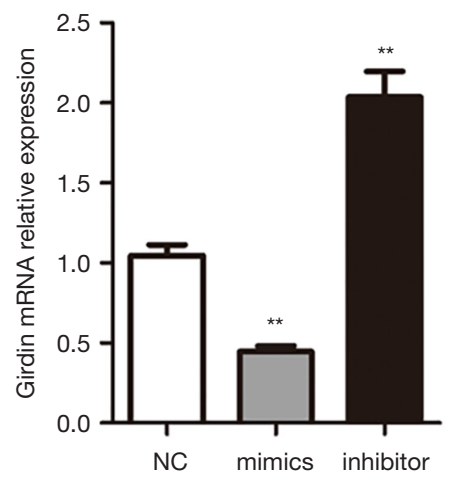

B

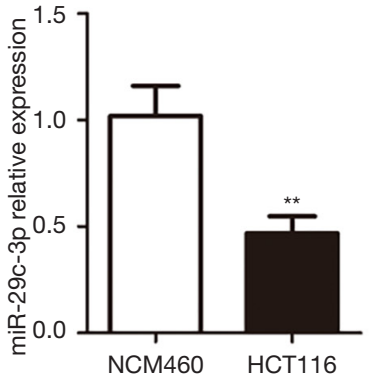

D
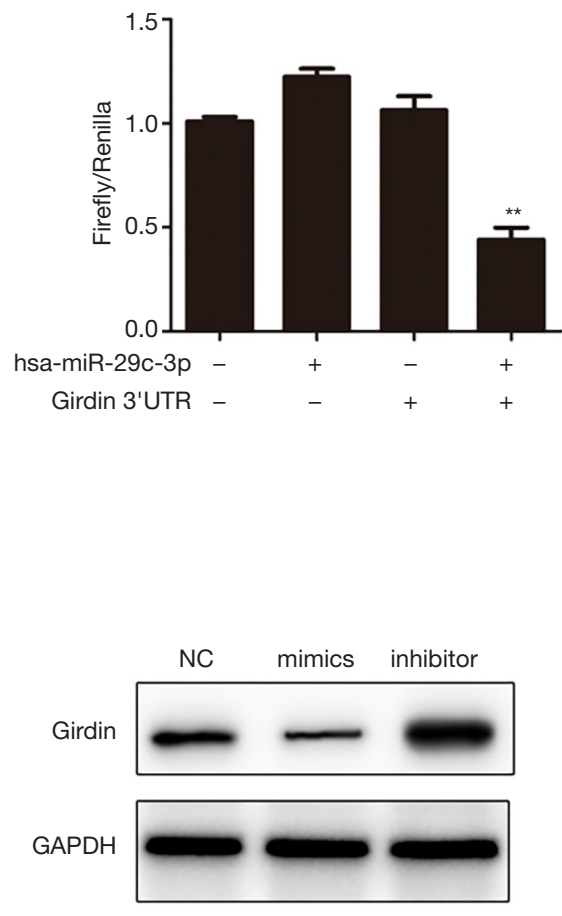

Figure 5 Girdin was a regulated target of hsa-miR-29c-3p in CRC. (A) The hsa-miR-29c-3p expression in COAD dataset of TCGA. (B) The levels of hsa-miR-29c-3p were detected in NCM460 and HCT116 ( $\mathrm{n}=3) .{ }^{* *} \mathrm{P}<0.01$ by two-tailed Student's $t$-test. (C) Binding site prediction by bioinformatics method and construction of dual-luciferase report plasmid. (D) Dual-luciferase reporter assay verified the regulation of hsa-miR-29c-3p and Girdin. (E) qRT-PCR and western blotting verified the effect of hsa-miR-29c-3p on the protein expression of Girdin $(\mathrm{n}=3),{ }^{* *} \mathrm{P}<0.01$ by two-tailed Student's $t$-test. CRC, colorectal cancer.

miR-29c-3p decreased compared with healthy colon tissue (Figure 5 A). qRT-PCR results confirmed that the expression of hsa-miR-29c-3p in HCT116 was significantly lower than that of NCM460 (Figure 5B). To accurately understand the regulation mechanism of hsa-miR-29c-3p and Girdin, the binding site by bioinformatics method was predicted and the dual-luciferase report plasmid psiCHECK2- Girdin was done (Figure 5C). co-transfected with psiCHECK2-Girdin 
and hsa-miR-29c-3p, it was found that the rate of firefly/ renilla was low in psiCHECK2- Girdin + hsa-miR-29c$3 \mathrm{p}$ group (Figure 5D). The results demonstrated that hsamiR-29c-3p could bind to 3'UTR of Girdin and reduced Girdin transcription. Girdin expression was decreased after overexpression of hsa-miR-29c-3p and increased after interference with hsa-miR-29c-3p. The protein expression trends were consistent with mRNA (Figure 5E).

\section{Discussion}

Girdin is an actin-binding protein. Its activation is via the serine/threonine kinase AKT and the protein acts in cytoskeleton remodeling as well as cell migration (14). Also, the encoded protein enhances Akt signaling. This enhancement is done by a mediation of the phosphoinositide 3-kinase (PI3K)-dependent activation of Akt via the growth, tyrosine kinases, factor receptor, and $G$ protein-coupled receptors $(15,16)$. Cancer metastasis might be determined by an increasing expression of this gene and phosphorylation of the encoded protein (17). Numerous studies have shown that the upregulation of Girdin is observed in many malignant tumors, such as gastric cancer, esophageal cancer, CRC, glioblastoma, breast cancer, etc., which suggest the oncological and clinical significance of Girdin (18), Our study revealed that Girdin contributed to proliferation, metastasis of CRC. IHC staining, WB and qRT-PCR showed that Girdin is greatly expressed for the CRC tissues when it was associated with that for contiguous normal squamous epithelium.

Earlier studies have shown the vital role of hsa-miR-29c$3 p$ in tumorigenesis and tumor progression. Wu et al. [2019] found that hsa-miR-29c-3p may directly target SPARC whose silencing reduced cell proliferation and migration. The expression of hsa-miR-29c-3p was significantly changed in multiple-tumors (19-21). It was the potential to become a molecular marker of CRC. In this study, we found that hsa-miR-29c-3p was down-regulated while Girdin expression was up-regulated. There was a strong correlation between hsa-miR-29c-3p and Girdin in COAD dataset of TCGA. Up-regulated hsa-miR-29c-3p declined the expression of Girdin through binding to 3'UTR. More importantly, patients with CRC with low expression of Girdin had a significantly longer survival time than patients with high expression. Our experimental results indicated that the hsa-miR-29c-3p/Girdin axis was a possible therapeutic target in carcinoma of colon and rectum.
Apoptosis, as programmed cell death, plays a crucial role in the development of healthy tissues and immune surveillance against cancer occurrence (22). Deregulation of apoptosis is one of the characteristics in the event of cancer (23). Therefore, induction of apoptosis in tumor cells is considered a therapeutic approach against cancer. Bax, Bak, and many other unknown proteins are moved into the mitochondrial outer membrane and then oligomerized to become the mitochondrial apoptosis-induced channel to release cyto $\mathrm{C}$ upon apoptotic stimulus. So, we examined changes in mitochondrial membrane potential and related proteins. The present study showed that chromatin condensation and nuclear and cytoplasmic fragmentation were observed in Girdin shRNA-transfected cells, which indicate cell apoptosis. Also, flow cytometry analysis revealed that apoptotic cells gradually increased after Girdin knockdown in HCT116 cells. The findings of the present study provide a theoretical basis for the role of Girdin in the genesis of CRC and a strategy for anti-CRC biotherapy.

\section{Acknowledgments}

Funding: This study was supported by Science and Technology Program Guangzhou, (No: 201904010020), China.

\section{Footnote}

Conflicts of Interest: All authors have completed the ICMJE uniform disclosure form (available at http://dx.doi. org/10.21037/tcr.2019.12.16). The authors have no conflicts of interest to declare.

Ethical Statement: The authors are accountable for all aspects of the work in ensuring that questions related to the accuracy or integrity of any part of the work are appropriately investigated and resolved.

Open Access Statement: This is an Open Access article distributed in accordance with the Creative Commons Attribution-NonCommercial-NoDerivs 4.0 International License (CC BY-NC-ND 4.0), which permits the noncommercial replication and distribution of the article with the strict proviso that no changes or edits are made and the original work is properly cited (including links to both the formal publication through the relevant DOI and the license). See: https://creativecommons.org/licenses/by-nc-nd/4.0/. 


\section{References}

1. Siegel RL, Miller KD, Fedewa SA, et al. Colorectal cancer statistics, 2017. CA Cancer J Clin 2017;67:177-93.

2. Yamashita YI, Baba H. How can we predict hepatic insufficiency after resection of colorectal liver metastases? Transl Cancer Res 2017;6:S1435-S8.

3. Chen CH, Chen D, Lin ZK, et al. Prognostic factors and outcomes of osseous chondrosarcoma after surgery: the 2004-2014 Surveillance, Epidemiology, and End Results database study. Transl Cancer Res 2018;7:341-6.

4. Jiang P, Enomoto A, Jijiwa M, et al. An actin-binding protein Girdin regulates the motility of breast cancer cells. Cancer Res 2008;68:1310-8.

5. Wang C, Lin J, Li L, et al. Expression and clinical significance of girdin in gastric cancer. Mol Clin Oncol 2014;2:425-8.

6. Zhao L, Ma S, Liu Q, et al. Clinical implications of Girdin protein expression in glioma. Scientific World Journal 2013;2013:986073.

7. Jiang P, Ren YL, Li JL, et al. Girdin expression in cervical carcinoma and its role in the malignant properties of HeLa cells. Oncol Lett 2016;11:2440-4.

8. Zhang YJ, Li AJ, Han Y, et al. Inhibition of Girdin enhances chemosensitivity of colorectal cancer cells to oxaliplatin. World J Gastroenterol 2014;20:8229-36.

9. Ludwig N, Leidinger P, Becker K, et al. Distribution of miRNA expression across human tissues. Nucleic Acids Res 2016;44:3865-77.

10. Dragomir MP, Knutsen E, Calin GA. SnapShot: Unconventional miRNA Functions. Cell 2018;174:1038.

11. Wang XW, Xi XQ, Wu J, et al. MicroRNA-206 attenuates tumor proliferation and migration involving the downregulation of NOTCH3 in colorectal cancer. Oncol Rep 2015;33:1402-10.

12. Zhang S, Jin J, Tian X, et al. hsa-miR-29c-3p regulates biological function of colorectal cancer by targeting SPARC. Oncotarget 2017;8:104508-24.

13. Hui S, Yang Y, Li J, et al. Differential miRNAs profile

Cite this article as: Wang J, Li X, Li Y, Yao X. Girdin knockdown promotes apoptosis in colorectal cancer via miR29c-3p/Girdin axis. Transl Cancer Res 2019;8(8):2906-2915. doi: $10.21037 /$ tcr.2019.12.16 and bioinformatics analyses in bone marrow mesenchymal stem cells from adolescent idiopathic scoliosis patients. Spine J 2019;19:1584-96.

14. Wang S, Lei Y, Cai Z, et al. Girdin regulates the proliferation and apoptosis of pancreatic cancer cells via the PI3K/Akt signalling pathway. Oncol Rep 2018;40:599-608.

15. Lei B, Sun S, Zhang X, et al. Bisphenol AF exerts estrogenic activity in MCF-7cells through activation of Erk and PI3K/Akt signals via GPER signaling pathway. Chemosphere 2019;220:362-70.

16. Viswanathan A, Kute D, Musa A, et al 2-(2-(2,4-dioxopentan-3-ylidene)hydrazineyl)benzonitrile as novel inhibitor of receptor tyrosine kinase and PI3K/ AKT/mTOR signaling pathway in glioblastoma. Eur J Med Chem 2019;166:291-303.

17. Li J, Enomoto A, Weng L, et al. Dephosphorylation of Girdin by PP2A inhibits breast cancer metastasis. Biochem Biophys Res Commun 2019;513:28-34.

18. Wang X, Enomoto A, Asai N, et al. Collective invasion of cancer: Perspectives from pathology and development. Pathol Int 2016;66:183-92.

19. Chen G, Zhou T, Li Y, et al. p53 target miR-29c-3p suppresses colon cancer cell invasion and migration through inhibition of PHLDB2. Biochem Biophys Res Commun 2017;487:90-5.

20. $\mathrm{Wu} \mathrm{H}$, Zhang $\mathrm{W}, \mathrm{Wu} \mathrm{Z}$, et al. miR-29c-3p regulates DNMT3B and LATS1 methylation to inhibit tumor progression in hepatocellular carcinoma. Cell Death Dis 2019;10:48.

21. Dong XZ, Song Y, Lu YP, et al. Sanguinarine inhibits the proliferation of $\mathrm{BGC}-823$ gastric cancer cells via regulating miR-96-5p/miR-29c-3p and the MAPK/JNK signaling pathway. J Nat Med 2019;73:777-88.

22. Bold RJ, Termuhlen PM, Mcconkey DJ. Apoptosis, cancer and cancer therapy. Surg Oncol 1997;6:133-42.

23. Peña-Blanco A, Garcia-Saez AJ. Bax, Bak and beyond - mitochondrial performance in apoptosis. FEBS J 2018;285:416-31. 